University of Nebraska - Lincoln

DigitalCommons@University of Nebraska - Lincoln

\title{
Multi-criteria decision analysis to select metrics for design and monitoring of sustainable ecosystem restorations
}

\author{
M. Convertino \\ University of Florida, mconvertino@ufl.edu \\ K.M. Baker \\ Engineer Research and Development Center \\ J.T. Vogel \\ Engineer Research and Development Center \\ C. Lu \\ Massachusetts Institute of Technology \\ B. Suedel \\ U.S. Army Corps of Engineers \\ See next page for additional authors
}

Follow this and additional works at: https://digitalcommons.unl.edu/usarmyresearch

Convertino, M.; Baker, K.M.; Vogel, J.T.; Lu, C.; Suedel, B.; and Linkov, I., "Multi-criteria decision analysis to select metrics for design and monitoring of sustainable ecosystem restorations" (2013). US Army Research. 190.

https://digitalcommons.unl.edu/usarmyresearch/190

This Article is brought to you for free and open access by the U.S. Department of Defense at DigitalCommons@University of Nebraska - Lincoln. It has been accepted for inclusion in US Army Research by an authorized administrator of DigitalCommons@University of Nebraska - Lincoln. 


\section{Authors}

M. Convertino, K.M. Baker, J.T. Vogel, C. Lu, B. Suedel, and I. Linkov 


\title{
Multi-criteria decision analysis to select metrics for design and monitoring of sustainable ecosystem restorations
}

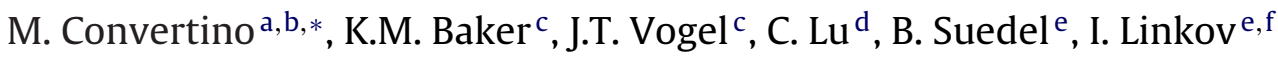 \\ a Department of Agricultural and Biological Engineering, University of Florida, Gainesville, FL, USA \\ ${ }^{\mathrm{b}}$ Florida Climate Institute, c/o University of Florida, Gainesville, FL, USA

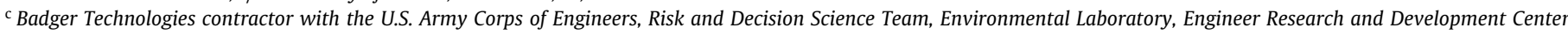 \\ (ERDC), Concord, MA, USA \\ ${ }^{\mathrm{d}}$ Department of Civil and Environmental Engineering, Environmental and Water Quality Program, Massachusetts Institute of Technology, Cambridge, MA, USA \\ ${ }^{\mathrm{e}}$ Risk and Decision Science Team, Environmental Laboratory, Engineer Research and Development Center (ERDC), U.S. Army Corps of Engineers, Vicksburg, MS, USA \\ ${ }^{\mathrm{f}}$ Department of Engineering and Public Policy, Carnegie Mellon University, Pittsburgh, PA, USA
}

\section{A R T I C L E I N F O}

\section{Article history:}

Received 28 February 2012

Received in revised form 2 October 2012

Accepted 8 October 2012

\section{Keywords:}

Multi-criteria decision analysis

Environmental metrics

Ecosystem restoration

Monitoring

Stakeholder preferences, utility

\begin{abstract}
A B S T R A C T
The selection of metrics for ecosystem restoration programs is critical for improving the quality and utility of design and monitoring programs, informing adaptive management actions, and characterizing project success. The metrics selection process, that in practice is left to the subjective judgment of stakeholders, is often complex and should simultaneously take into account monitoring data, environmental models, socio-economic considerations, and stakeholder interests. With limited funding, it is often very difficult to balance the importance of multiple metrics, often competing, intended to measure different environmental, social, and economic aspects of the system. To help restoration planners and practitioners develop the most useful and informative design and monitoring programs, we propose the use of multi-criteria decision analysis (MCDA) methods, broadly defined, to select optimal ecosystem restoration metric sets. In this paper, we apply and compare two MCDA methods, multi-attribute utility theory (MAUT), and probabilistic multi-criteria acceptability analysis (ProMAA), for a hypothetical river restoration case study involving multiple stakeholders with competing interests. Overall, the MCDA results in a systematic, quantitative, and transparent evaluation and comparison of potential metrics that provides planners and practitioners with a clear basis for selecting the optimal set of metrics to evaluate restoration alternatives and to inform restoration design and monitoring. In our case study, the two MCDA methods provide comparable results in terms of selected metrics. However, because ProMAA can consider probability distributions for weights and utility values of metrics for each criterion, it is most likely the best option for projects with highly uncertain data and significant stakeholder involvement. Despite the increase in complexity in the metrics selection process, MCDA improves upon the current, commonlyused ad-hoc decision practice based on consultations with stakeholders by applying and presenting quantitative aggregation of data and judgment, thereby increasing the effectiveness of environmental design and monitoring and the transparency of decision making in restoration projects.
\end{abstract}

(C) 2012 Elsevier Ltd. All rights reserved.

\section{Introduction}

In the context of ecosystem restoration projects, metrics are measurable system properties that characterize the system and quantify the impact of restoration activities, possibly at different life stages of restorations (Allen et al., 1997; U.S. Army Corps of Engineers, 1999; Nienhuis et al., 2002; Reichert et al., 2007;

\footnotetext{
* Corresponding author at: Department of Agricultural and Biological Engineering and Florida Climate Institute, Frazier Rogers Hall, Museum Road, PO box 110570 , 32611-0570, USA. Tel.: +1 781645 6070; fax: +1 3523924092.

E-mail address: mconvertino@ufl.edu (M. Convertino).
}

Seager et al., 2007; Martine and Cockfield, 2008; McKay et al., 2011) Thoughtful, appropriate metrics selection is key to effectively characterizing the system, selecting a restoration strategy or a single restoration among a set of restoration alternatives, and understanding the effects of project actions on the system (Ehrenfeld, 2000). Appropriate, clearly defined metrics should reduce uncertainty, increase knowledge of the system and assess the usefulness of applied restoration alternatives by creating a targeted, effective means of evaluation. The evaluation of a restoration alternative can occur both pre- and post-execution (Holmes, 1991), and it is certainly important considering the variability of climate and other anthropic factors (Palmer et al., 2008). For example, a monitoring plan based on sound metrics can demonstrate progress and 
the degree to which objectives of a restoration are being met to leadership, stakeholders, and future project sponsors, increase the depth and breadth of understanding about the effects of ecosystem restoration practices, contribute to expanding knowledge about ecosystems, and guide management decisions on the most effective, efficient, and cost-effective courses of action (Kondolf, 1995; Thom and Wellman, 1996; U.S. Army Corps of Engineers, 1999; Grootjans et al., 2002; Rohde et al., 2004). The same considerations are true for design plans that aim to change the configuration of environmental systems at the initial or intermediate steps of ecosystem restorations.

The complexity of ecological systems and restoration objectives gives rise to a multitude of potential ecosystem monitoring metrics. Extensive lists of monitoring metrics provide hundreds of potential options, often with numerous choices for just one specific ecosystem characteristic (Thayer et al., 2005; Faber-Langendoen et al., 2006). For example, NOAA's Tools for Monitoring Coastal Habitats provides fifteen different metrics to monitor whether a mangrove habitat "supports a complex trophic structure" alone, including biological, geographical, hydrological, and chemical metrics as well as others (Thayer et al., 2005). However, with limited funding, it may only be possible to effectively measure, estimate, or otherwise use a few metrics, so it is critical to select the metrics that can most clearly indicate the state of the system and changes in relation to project goals.

Metrics selection is thus a challenging process. The optimum choice of metrics will depend on a number of factors including multiple project objectives, technical feasibility, effectiveness, communicability, and stakeholder preferences. Balancing and evaluating these factors with respect to each metric choice is a difficult task that requires a comprehensive, practical metrics selection method. There are a number of commonly used methods for metrics selection, including best professional judgment, historical precedence, conceptual modeling, screening using established criteria sets, and Analytic Hierarchy Process models (AHP) (Saathy, 1980; Dale and Beyeler, 2001; Niemeijer and de Groot, 2008; Linkov and Moberg, 2011; Convertino et al., 2012; Mexas et al., 2012). Here we briefly describe only the most commonly used methods and refer the reader to more extended review papers for additional methodology (see for example Linkov and Moberg, 2011).

The use of best professional judgment (BPJ) is generally inexpensive and time-efficient and may be an appropriate metrics selection method for small, well-understood projects. However, metrics selection via this method may exclude or place bias on specific stakeholder values, and becomes exceedingly difficult as project complexity increases. Another weakness of both best professional judgment and historical precedence is lack of transparency, which makes the decision-making more difficult to document and justify (Dale and Beyeler, 2001; Niemeijer and de Groot, 2008).

Historical precedence constitutes selection of metrics that have been previously utilized in similar ecosystem restoration programs (e.g. those with similar objectives, with similar regional or ecological characteristics, that respond to similar disturbances, and/or involve similar stakeholders). Maintaining the use of historical metrics often allows for easy comparison to baseline data and cross-comparison among projects, and may involve lower initial investment than developing new metrics. However, metrics selection via this method may encourage project planners to overlook well-suited and site-specific metrics in favor of less appropriate but more familiar metrics.

As a more transparent alternative or supplement to best professional judgment and historical precedence, restoration project managers may sometimes evaluate or "screen" potential metrics against a set of criteria to identify the most appropriate subset of metrics for a given project. Screening is relatively inexpensive and time-efficient, and criteria are well-documented. Screening is a more structured metrics selection method than best professional judgment and historical precedence, but is generally not adequate as a standalone method. Screening does not facilitate formal consideration of a metric's utility within the total collection of its metrics set, as most criteria are meant to apply to metrics individually (Niemeijer and de Groot, 2008). In particular, there is no a quantitative internal structure for determining whether a metrics set is comprehensive.

Analytical Hierarchy Process is a controversial method for alternative selection developed by Saaty, 1980. To the best of our knowledge it was never used in selection of metrics as alternatives of the decision problem. However, AHP has been used in a variety of environmental management problems (Linkov and Moberg, 2011; Huang et al., 2011). Because AHP is based on a subjective pairwise comparison of criteria, rather than using value functions and normalized weights, it has been criticized for its measurement scale, rank reversal, and transitivity of preferences (Gass, 2005; Yatsalo et al., 2007).

To improve the efficacy of ecosystem restoration design and monitoring programs (Linkov and Moberg, 2011), we suggest the application of MCDA, a decision-making analysis based on decision science theory (Keeney and Raiffa, 1976) that can quantitatively evaluate alternatives (i.e. metrics in our case) based on their utility value for stakeholders with respect to defined criteria, and the relative importance of those criteria (Drechsler et al., 2003; Linkov and Moberg, 2011). Applied correctly, MCDA methods will result in the most useful metric set for evaluating stated project priorities, which would enable project managers to make comprehensive, well-informed decisions, and allow researchers and practitioners to improve and update the principles that guide restoration practices. We believe that a formal MCDA-based method is largely useful and needed for the selection of metrics that can be used in evaluating restoration alternatives or monitoring alternatives of restorations. Tsoutsos et al. (2009) provides several reasons that justify MCDA for use in complex decisions with similar factors to consider. MCDA is appropriate for complex decisions because: (a) it enables integration of interests and objectives of multiple players, since all of this information can be accounted for in the form of criteria and weight factors (Pohekar and Ramachandran, 2004; Sigrid, 2004; Loken, 2007; Tsoutsos et al., 2009); (b) it deals with the complexity of having multiple stakeholders by providing easily understandable outputs, and, by virtue of working systematically, is transparent and user-friendly (Georgopoulou et al., 1997; Tsoutsos et al., 2009); and (c) it is well-documented and a large number of different MCDA methods have been applied in a wide range of decisions (Phillis and Andriantiatsaholiniana, 2001; Kaminaris et al., 2006; Diakoulaki and Karangelis, 2007; Tsoutsos et al., 2009; Linkov and Moberg, 2011). Here, we expand the application of MCDA techniques by developing and applying a MCDA framework for evaluating and ranking ecosystem restoration metrics designed to characterize the system and quantify the effects of project actions.

In this paper, we introduce the framework for using MCDA for ecosystem restoration metrics selection and illustrate its application to a hypothetical restoration case study which we call the "Black River Restoration Project". Our case study resembles a realistic ecosystem because we consider all the components typically present in a river ecosystem. The paper is structured as follows. Materials and Methods describe the hypothetical case study and the development of the components of the MCDA models. In the same section we introduce the theoretical background of the deterministic and stochastic multi criteria decision models (MAUT and ProMAA). Results and Discussion present the results of the domination analysis and metric alternative rankings. We also provide a comparative assessment of both MCDA models applied to the case study. The Conclusions section discusses the benefits and 
limitations of utilizing MCDA for metrics selection and the most appropriate circumstances in which to apply this new methodology.

\section{Materials and methods}

This paper builds on metrics selection methodology proposed by Linkov and Moberg (2011) and tailors it specifically for evaluation of ecosystem restoration monitoring metrics. Two MCDA methods, MAUT and ProMAA, were utilized to rank metrics for monitoring and evaluating a hypothetical river restoration project in which the coupling between human and natural systems is very high.

\subsection{Hypothetical aquatic ecological restoration}

The Black River is a hypothetical perennial river with a broad floodplain consisting of impermeable surfaces, cottonwood forests, aquatic wetlands, bare soils, and the river network. Fig. 1 represents a schematic view of the hypothetical Black River and its land cover categories. Over the past several decades, the river and floodplain have undergone significant changes due to urbanization and dam construction. The cumulative effect of these stressors is the disruption of the original hydrologic regime, main stem channelization, and reduced river-floodplain interaction, which has increased fire and flood hazards, reduced wildlife habitat quality and quantity, decreased biodiversity, and facilitated encroachment of harmful exotic plants. In partnership with state authorities, federal government institutions are planning an ecosystem restoration project with the goal of increasing ecosystem quality by restoring the structure and function of the Black River floodplain ecosystem.

A multi-agency (federal, state, and local government, academia, NGOs, and private consultants), multi-disciplinary (ecologists, hydrologists, geologists, engineers, economists) team was assembled to set objectives, develop a conceptual model, identify an approach for assessing environmental benefits, formulate and evaluate restoration alternatives to address degradation of the Black River floodplain, and develop an effective monitoring program to track system changes and evaluate project success. The latter task depended on selecting the most appropriate metrics to assess how well project objectives were being met. As the project involves a complex system with multiple objectives and stakeholders, the team chose to use MCDA methodology to guide their selection of the optimal metric set.

\subsection{Multi-criteria decision analysis (MCDA)}

MCDA is a structured approach to decision-making that quantitatively evaluates alternatives, in this case, metrics, based on defined project criteria, expert opinions, and stakeholder preferences (Linkov and Moberg, 2011; Wood et al., 2012). It integrates a wide variety of information to evaluate project alternatives and rank them based on their aggregated value with respect to a set of criteria (Linkov and Moberg, 2011). It usually consists of four stages. The project team, incorporating expert and stakeholder opinions, must define: (1) the set of possible decision alternatives (in this case, metric alternatives) to be evaluated and ranked; (2) the criteria of the value tree that will influence the decision that these alternatives will be evaluated against; (3) the importance of each criterion relative to the others or their "weight" followed by a normalization of weights performed separately for each order of criteria (criteria of order one, criteria of order two (or sub-criteria), etc.); and (4) the value of each alternative with respect to each criterion. Depending on the specific MCDA method, (3) and (4) may also include uncertainty estimates.

In MCDA methods that incorporate utility theory (Keeney and Raiffa, 1976) the values in (4) for each criterion are transformed into utility values according to utility functions for each criterion. Utility functions are expressions of stakeholder preferences of alternatives as a function of each criterion (Keeney and Raiffa, 1976) that are usually assessed by direct methods (e.g. interviews (Keeney, 1977)), or indirect methods (e.g. serious games (Braziunas, 2012)).

Restoration planners and stakeholders should determine the criteria and the relative importance (weighting) of each criterion, while appropriate professionals and field experts should create the potential alternatives pool, and determine the value of each alternative with respect to each criterion. Using this information, MCDA software can be used to first eliminate dominated alternatives, or those alternatives that are less valuable than at least one other alternative with respect to every decision criterion, and then to rank those remaining. The rank is an ordinal number in the range $[1, n]$,

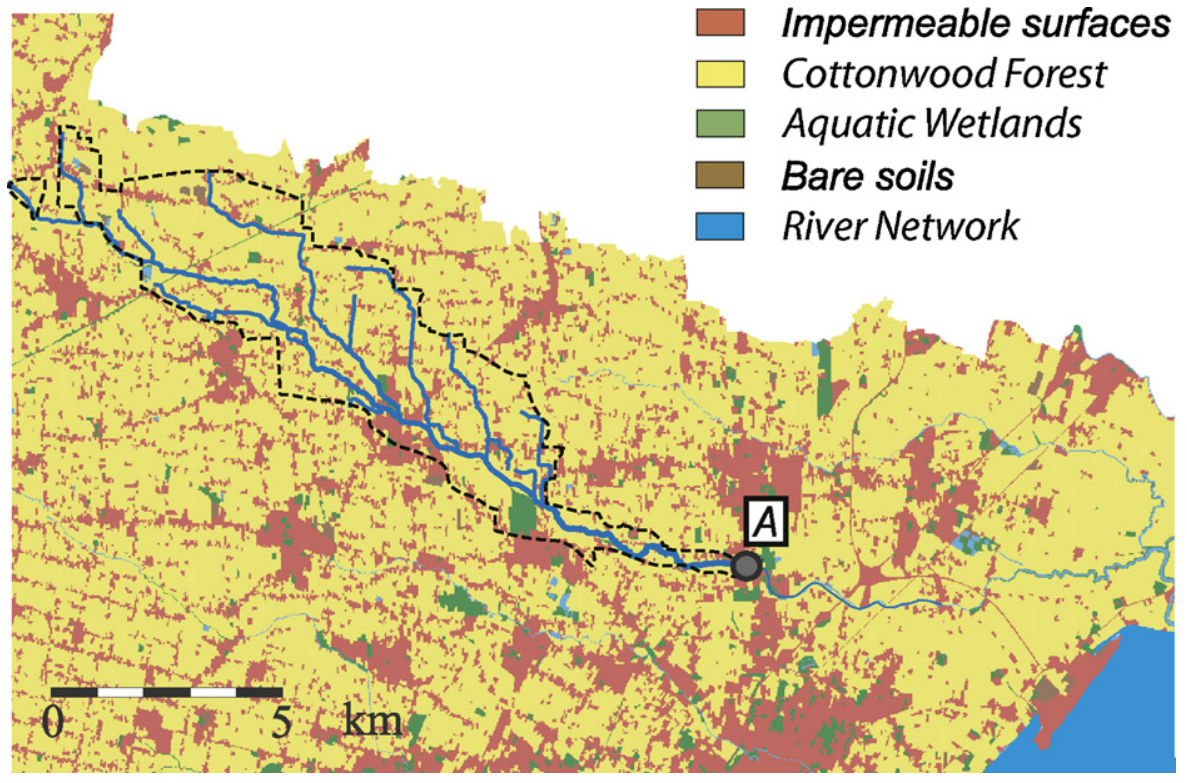

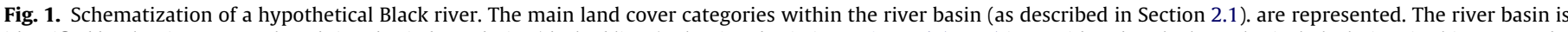

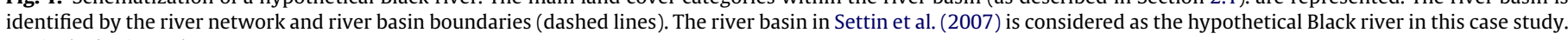
"A" is the basin outlet. 
where $n$ is the number of metrics, assigned as a function of the decreasing utility. The higher the utility, the lower the rank.

In the case of the Black River restoration, the MCDA analysis was used to narrow down and rank an initially large set of aquatic ecosystem monitoring metric alternatives based on their ability to provide information about system characteristics related to project objectives (the criteria) and stakeholder preferences for those objectives (the weights). We consider stakeholders to be all the people that have a stake in the environmental problem considered as suggested in Wood et al. (2012).

We utilized the MCDA software DECERNS-SDSS (Decision Evaluation in ComplEx Risk Network Systems-Spatial Decision Support System) (Yatsalo, 2011) to model the problem space and analyze the input data. The idea behind DECERNS-SDSS is that systems are complex due to the high degree of interconnections among system components and because of the multiplicity of risks affecting these systems (Linkov and Moberg, 2011; Yatsalo, 2011). The software was developed by Yatsalo (2011) supported by the Risk and Decision Science Team of the U.S. Army Corps of Engineers (Linkov and Moberg, 2011). A demonstration version of the model and the case study is included in this paper in the Supplementary Material. For further information we refer the reader to Linkov and Moberg (2011).

The hypothetical monitoring goal of the optimal set of metrics is twofold: (i) to select the best restoration alternative; and, (ii) to evaluate restoration project success by measuring the degree to which the intended objectives have been achieved following the project implementation period. To begin the MCDA analysis of metric alternatives, we first defined the set of project objectives, or intended benefits, in order to develop the model criteria at different orders of the value tree (Table 1). In this case study we develop criteria until the second order in the value tree; thus, we refer to criteria and sub-criteria. Objectives vary from project to project, but generally include environmental, economic, socio-political, and public health and safety considerations (Linkov and Moberg, 2011). From the objectives of the hypothetical project, we derived a set of criteria and sub-criteria against which we later evaluated the utility of each potential metric. The metric alternatives that performed best based on these criteria and sub-criteria were considered to be the most useful in characterizing important project aspects and measuring fulfillment of specific ecosystem restoration objectives.

The results of the criteria and alternative development are represented in DECERNS-SDSS by a structured value tree (Fig. 2) showing the overall objective, criteria, sub-criteria, and nondominated metric alternatives. Note that, on the contrary of AHP methods, the tree can be asymmetric (e.g. a different number of criteria of order two for each criterion) and the assignment and normalization of weights is performed separately for criteria and sub-criteria. In this case, it is possible to compare the weights of criteria but not the weights of criteria and sub-criteria because they are normalized at their respective level in tree.

Chosen criteria depend on clear, well-defined project objectives and should be comprehensive, including all aspects relating to project success as well as any additional system characteristics of interest. Yet, we believe that a sustainable paradigm for restorations should be adopted considering that components, services, and risks of ecosystems are highly interconnected (Pauly et al., 2002; Clark, 2007; Bettencourt and Kaur, 2011; World Economic Forum, 2011; National Academy of Sciences, 2012). Thus, in our case study we included environmental (hydrological, geomorphological, geological, ecological, biochemical), social, and economic criteria (Table 1). Health criteria have been considered separately because they can be part of both social and environmental criteria case by case depending on the drivers of health issues in the ecosystem analyzed (Clark, 2007; National Academy of Sciences, 2012).
The general criteria selected give a good indication of the state of the environment and the environmental effects of restoration measures. Some of these criteria included more detailed subcriteria such as recreation and maintenance under economy. The use of sub-criteria allows stakeholders to weight both the general category (e.g., economy) and more detailed aspects that relate to specific stakeholder concerns. Criteria formulation is an important step in defining what is important to project success and what should be considered in the decision making process. More criteria, sub-criteria, and criteria of higher order could have been considered for this project, but the current set gives an adequate indication of the state of the system and progress toward objectives.

Once the taxonomy of criteria and sub-criteria was established, the project team then developed an initial, comprehensive set of general aquatic ecosystem monitoring metrics related to each criterion (Table 1). The set of metrics to be selected should be as holistic

Table 1

Initial list of potential metrics for aquatic ecosystems, organized into functional categories. Each category of metrics can be thought of as an ecosystem service class Ecosystem services can be grouped in sustainability classes (Environmental, Social, and Economical). Each initial potential metric is then considered dominated, nondominated, or equal to another metric according to a Pareto domination analysis (Section 2.2). The 43 metrics constitute an exhaustive list according to the stakeholders (i.e. the authors in this case study) involved in the hypothetical Black river restoration.

\begin{tabular}{ll}
\hline & Metrics \\
\hline Hydrological & Water Table Level \\
& Soil Moisture \\
& Bankfull Discharge \\
& Hydroperiod \\
& Flooding Return Period 100-years \\
& Flooding Frequency 1-year Runoff \\
& Flooding Frequency 2-year Runoff \\
& Minimum Water Flow \\
& River Salinity \\
& Maximum Elevation Gradient \\
& River Basin Extension \\
& Floodplain Extension \\
Average Riparian Width & Hack's Exponent \\
Heomorphological & Hillslope Stability Factor \\
& Sediment Discharge \\
& Species Area Exponent \\
Local Species Richness \\
Regional Species Richness \\
Pairwise Species Richness Similarity \\
Species Abundance \\
Average Landscape Connectivity \\
p/A Patch Ratio \\
Canopy Evapotranspiration \\
Habitat Area Songbird \\
Geographic Range Songbird \\
Habitat Area Fishes \\
Number Invasive Species \\
Metapopulation Risk \\
\end{tabular}

Geological

Granulometric Curve Conductivity

Biochemical

Total Maximum Daily Load

$\mathrm{N} \%$

$\mathrm{P} \%$

$\mathrm{C} \%$

$\mathrm{O} \%$

$\mathrm{PH}$

Microbial Biomass

Bioaccumulation Potential

Socio-economical Number Visits/Year

Number of Trails

Health

Number of Epidemics last 10 years 


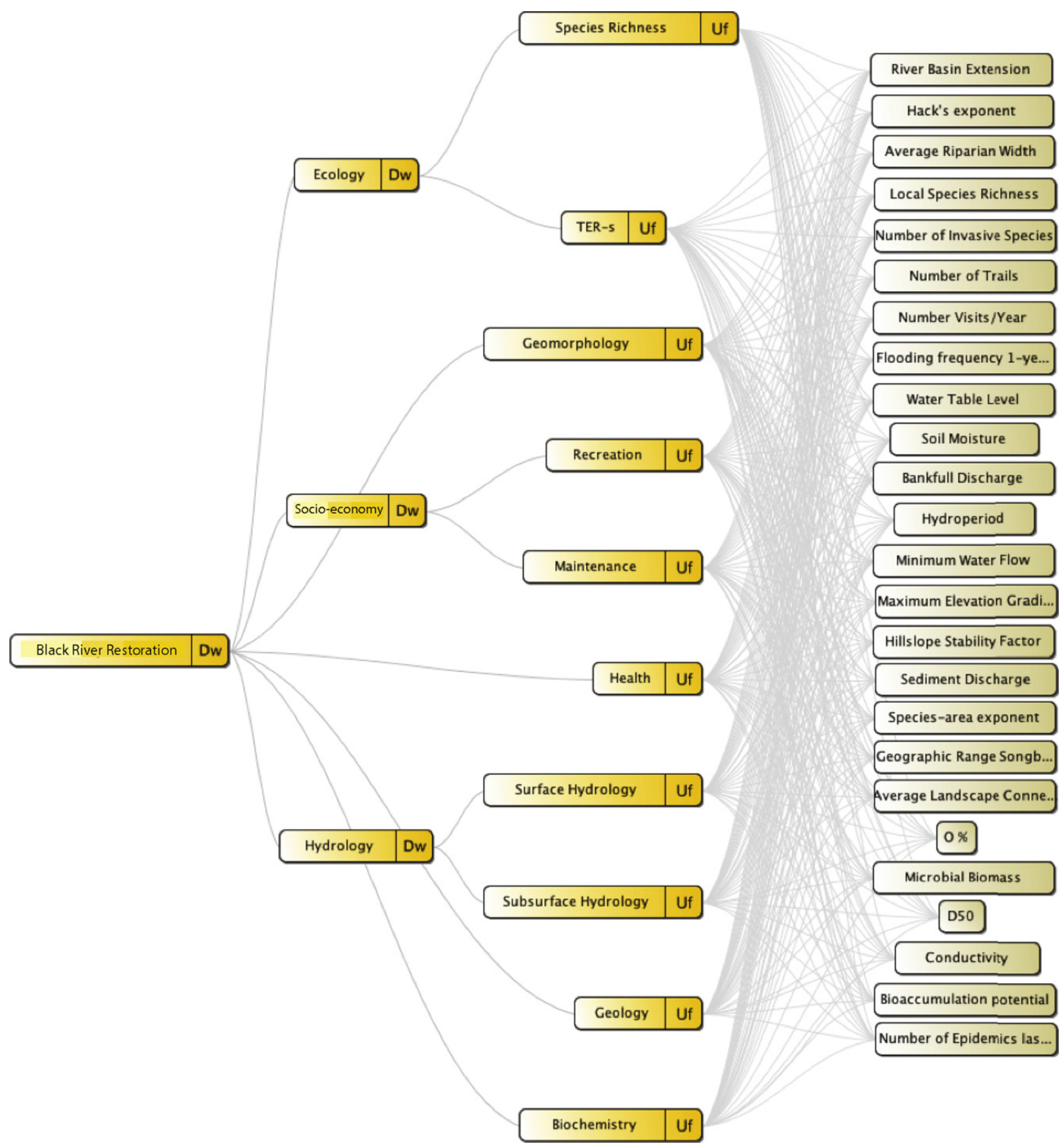

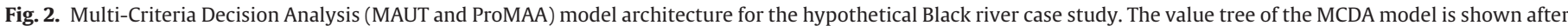

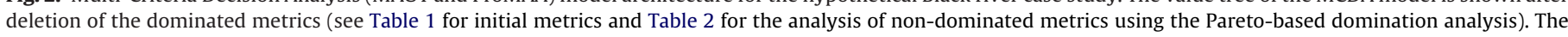

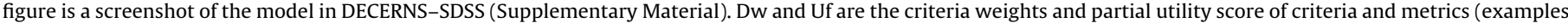
are in Figure S1, S2 and S3 respectively). In the theoretical formulation of the model (Sections 2.3 and 2.4 ) Dw and Uf are indicated as $w_{j}$ and $U_{j}\left(a_{i}\right)$ respectively.

as possible in order to guarantee that the most important metrics are considered.

The potential metrics pool can be adjusted as new information in the field of environmental and socio-economical management becomes available or, in some projects, restoration managers may find it beneficial to adjust the potential metrics pool to account for project-specific objectives. This would certainly be necessary when considering very specific objectives such as increasing the population of a specific endangered species. Moreover the metrics pool can be also adjusted when project-specific objectives are shifted in time.
In practice, environmental practitioners, scientists and other experts are then consulted to evaluate the utility of each potential metric in measuring fulfillment of each criterion. In MCDA terminology, this is to say that the analysts assign each metric a score, or partial "utility", for each criterion. In the case study presented in this paper, the authors provided the scores using their best knowledge of aquatic ecosystem function and structure. In Supplementary Material (Fig. S1) we report an example of scores for the hydroperiod as a function of each criterion.

Next, the team ran an MCDA "domination analysis" to identify and remove metrics that were dominated by one or more others 
Table 2

Pareto-based domination analysis. The table reports the non-dominated (white lines), dominated (dark gray lines), and equivalent metrics (light gray lines). Equivalent metrics are characterized by the same utility for the objective of the decision problem that is the Black river restoration. The overall utility, $U\left(a_{i}\right)$, of the 25 nondominated alternatives is calculated by the MCDA methods (MAUT and ProMAA) (Sections 2.3 and 2.4 respectively). The metric index is for a better readability of the table. The initial list of metrics is in Table 1.

\begin{tabular}{|c|c|c|}
\hline Metric Index & Metric name & Domination \\
\hline 1 & River Basin Extension & Non-dominated \\
\hline 2 & Hack's Exponent & Non-dominated \\
\hline 3 & Average Riparian Width & Non-dominated \\
\hline 4 & Floodplain Extension & $\begin{array}{l}\text { Dominated by River } \\
\text { Basin Extension }\end{array}$ \\
\hline 5 & Local Species Richness & Non-dominated \\
\hline 6 & Metapopulation Risk & $\begin{array}{l}\text { Dominated by } \\
\text { Number of Invasive } \\
\text { Species }\end{array}$ \\
\hline 7 & Number of Invasive Species & Non-dominated \\
\hline 8 & Habitat-area Fishes & $\begin{array}{l}\text { Dominated by Local } \\
\text { Species Richness }\end{array}$ \\
\hline 9 & Habitat-area Songbird & $\begin{array}{l}\text { Dominated by Local } \\
\text { Species Richness }\end{array}$ \\
\hline 10 & Number of Trails & Non-dominated \\
\hline 11 & Number of Visits/Year & Non-dominated \\
\hline 12 & Flooding Frequency 1-year Runoff & $\begin{array}{l}\text { Equals with } \\
\text { Flooding Frequency }\end{array}$ \\
\hline 13 & Flooding Frequency 2-year Runoff & $\begin{array}{l}\text { 2-year Runoff } \\
\text { Non-dominated }\end{array}$ \\
\hline 14 & Water Table Level & Non-dominated \\
\hline 15 & Soil-moisture & Non-dominated \\
\hline 16 & Bankfull Discharge & Non-dominated \\
\hline 17 & Hydroperiod & Non-dominated \\
\hline 18 & Minimum Water Flow & Non-dominated \\
\hline 19 & Floodplain Return Period 100-years & $\begin{array}{l}\text { Dominated by } \\
\text { Flooding Frequency } \\
\text { 1-year Runoff }\end{array}$ \\
\hline 20 & River Salinity & $\begin{array}{l}\text { Dominated by } \\
\text { Water Table Level }\end{array}$ \\
\hline 21 & Maximum Elevation Gradient & Non-dominated \\
\hline 22 & Hillslope Stability Factor & Non-dominated \\
\hline 23 & Sediment Discharge & Non-dominated \\
\hline 24 & Species-area Exponent & Non-dominated \\
\hline 25 & Regional Species Richness & $\begin{array}{l}\text { Dominated by Local } \\
\text { Species Richness }\end{array}$ \\
\hline 26 & Pairwise Species Richness Similarity & $\begin{array}{l}\text { Dominated by Local } \\
\text { Species Richness }\end{array}$ \\
\hline 27 & Species Abundance & $\begin{array}{l}\text { Dominated by Local } \\
\text { Species Richness }\end{array}$ \\
\hline 28 & Geographic Range Songbird & Non-dominated \\
\hline 29 & Average Landscape Connectivity & Non-dominated \\
\hline 30 & P/A Patch Ratio & $\begin{array}{l}\text { Dominated by Local } \\
\text { Species Richness }\end{array}$ \\
\hline 31 & Canopy Evapotranspiration & $\begin{array}{l}\text { Dominated by } \\
\text { Flooding Frequency } \\
\text { 1-year Runoff }\end{array}$ \\
\hline 32 & Total Maximum Daily Load & $\begin{array}{l}\text { Dominated by } \\
\text { Microbial Biomass }\end{array}$ \\
\hline 33 & $\mathrm{~N} \%$ & Equals with $\mathrm{P} \%$ \\
\hline 34 & $\mathrm{P} \%$ & Dominated by $\mathrm{O} \%$ \\
\hline 35 & $\mathrm{C} \%$ & Dominated by $\mathrm{N} \%$ \\
\hline 36 & $\mathrm{O} \%$ & Non-dominated \\
\hline 37 & $\mathrm{PH}$ & Dominated by $0 \%$ \\
\hline 38 & Microbial Biomass & Non-dominated \\
\hline 39 & D50 & Non-dominated \\
\hline 40 & Granulometric Curve & Dominated by D50 \\
\hline 41 & Conductivity & Non-dominated \\
\hline 42 & Bioaccumulation Potential & Non-dominated \\
\hline 43 & Number of Epidemics Last 10 Years & Non-dominated \\
\hline
\end{tabular}

(Table 2). Dominated metrics were those that were outperformed (had lower value scores) by at least one other metric in all criteria. These metrics were eliminated as they would not be selected under any weighting scenario. The result of this step was a smaller set of non-dominated metrics which were then analyzed and ranked.
Specifically DECERN-SDSS implements a Pareto dominance method (Yatsalo, 2011). A feasible combination of metrics for a collection of objectives is said to be Pareto dominated if there does exist another feasible combination of metrics under which each objective is at least as well off and some objective is strictly better off (Emmerich and Deutz, 2006). Domination comparison is a purely a multi-objective metric comparison that gives some indication of which of two metric sets is closer to the Pareto front.

After the domination analysis, restoration manager and stakeholder preferences need to be elicited to establish the relative importance of each criterion and sub-criterion. The relative extents to which managers and stakeholders value various project objectives translate to the relative weights of the corresponding criteria and sub-criteria. Because this investigation utilized a hypothetical case study, we did not have access to a group of restoration practitioners and stakeholders. Instead of practitioner and stakeholder elicitation, we assigned hypothetical weights to each of the criteria and sub-criteria, based on what we believed were reasonable aquatic ecosystem restoration priorities. In practice, stakeholders would be interviewed or tested to determine their relative preferences for each criterion. Supplementary Material reports the tables containing the weights of criteria and sub-criteria for the restoration of the Black River (Figs. S2 and S3 respectively; the example of hydrological sub-criteria is reported). In Figs. S2 and S3 it is possible to observe the normalization of the weights in a $[0,1]$ range.

For preference weighting, we assumed the stakeholders were more sensitive to ecological problems and therefore assigned the highest weights to ecology, and to those criteria with the largest habitat impact. The normalized weight values are: 0.22 for ecology, 0.17 for geomorphology and hydrology, 0.14 for economy and health, 0.11 for geology, and 0.05 for biochemistry. These normalized weights always sum to one. These weights are highly dependent on which stakeholders' views are incorporated, so it is critical to involve a variety of stakeholders to capture the full suite of preferences for project outcomes. In general the aggregated weights representing all the stakeholders involved are the average values of all the individual stakeholder weights for each criterion (Keeney and Raiffa, 1976). In reality these weights are characterized by uncertainty and may vary in time. The MCDA method, ProMAA, is capable of handling weight uncertainty. On the contrary, MAUT is only capable of evaluating the uncertainty related to the utility assigned to each alternative for each criterion and not the uncertainty related to the stakeholders' preferences (weights). Here we do not consider the variability of stakeholder preferences among group of stakeholders and in time.

The input data are complete once the (1) taxonomy of criteria and sub-criteria; (2) pool of potential metrics; (3) partial utility values; and (4) weights, are formulated. An MCDA is then run using decision support software such as DECERNS-SDSS (Yatsalo et al., 2007) which will rank the potential metrics in terms of their overall utility to the set of weighted project objectives. Details of metric ranking will be explained further in the specific method sections below where we report the analytical characterization of MAUT, and ProMAA methods used to rank metric alternatives.

\subsection{Multi-attribute utility theory (MAUT)}

The Multi-Attribute Utility Theory (MAUT) resolves multiple preferences and value scores into an overall utility value for each metric alternative, enabling comparison. In this case, the utility of a given metric for measuring fulfillment of a specific aspect of the project objective was treated as a partial utility. To calculate an overall utility for each potential metric, the partial utility values were combined based on the relative importance of the component aspects of the objectives to the stakeholders (the weighting of criteria of different order in the value tree). MAUT considers uncertainty 
related to the utility assigned to each metric for each criterion, but does not consider the uncertainty related to the stakeholders' preferences (weights) (von Winterfeldt and Edwards, 1986; Belton and Stewart, 2002a,b).

To calculate the overall utility for each metric alternative, first let the set of potential metrics alternatives be $A=\left\{a_{i}, i=1, \ldots, n\right\}$ and the set of criteria be $C=\left\{c_{j}, j=1, \ldots, m\right\}$. Using the MAUT method (Keeney and Raiffa, 1976), each metric alternative, $a_{i}$, is ranked based its overall utility, $U\left(a_{i}\right)$ :

$U\left(a_{i}\right)=f\left(U_{1}\left(a_{i}\right), \ldots, U_{j}\left(a_{i}\right)\right)$

where $U_{j}\left(a_{i}\right)$ is the utility of alternative $a_{i}$ with respect to criterion $c_{j}$ of any order in the value tree. The generic MAUT function (Eq. (1)) may take on multiple functional forms (Keeney and Raiffa, 1976; Keeney and Gregory, 2005). For this paper, we assume that the partial utilities are independent, and utilize the additive form, which is widely used for practical MAUT applications. The functional form of the overall utility of metric alternative $a_{i}, U\left(a_{i}\right)$, is:

$U\left(a_{i}\right)=w_{1} U_{1}\left(a_{i}\right)+\cdots+w_{j} U_{j}\left(a_{i}\right)$,

with the normalization condition,

$\sum_{j=1}^{m} w_{j}=1, \quad w_{j}>0$,

where $w_{j}$ is a weighting factor representing the importance of criterion $c_{j}$ in the project. In DECERNS-SDSS the weight $w_{j}$ and the partial utility $U_{j}\left(a_{i}\right)$ are indicated as Dw and Uf respectively (Fig. 2).

MAUT can use distributions for alternative utility scoring (i.e. the "partial utility", $U_{j}\left(a_{i}\right)$ ), but can only use point values for weights and thus the uncertainty related to stakeholder preferences cannot be considered.

Despite extensive use of the expected utility concept, its use is not universally accepted, and other approaches that do not use expected utility methods are often implemented (Brans and Vincke, 1985; von Winterfeldt and Edwards, 1986; Belton and Stewart, 2002a,b; Figueira et al., 2005; Tervonen and Figueira, 2008). However, in metrics selection problems, like evaluating site characteristics and restoration project success, we believe that the utility value of a metric, rather than the expected value of multiple metrics for a variety of scenarios and criteria, is the best way to describe the aspect of the ecosystem corresponding to each criterion. This is because same values of criteria can have different utilities for different stakeholders. Thus, the elicitation of utility functions and the translation of values to utilities is an extremely important step for selecting and evaluating restoration (Keeney and Raiffa, 1976).

For uncertainty considerations, a normal distribution was considered for the utility weight value with average ranging from 0 to 10 proportionally to the importance of each metric with respect to each criterion. A standard deviation from 0.1 to 0.01 was considered from the average value according to the uncertainty in the utility of each metric in describing each criterion. The utility values and the standard deviations have been assessed by the authors of this paper (environmental engineers (M.C., K.B., and C.L.), a biologist (B.S.), an ecotoxicologist (I.L.), and an ecologist (J.V.)) in order to reduce the subjective uncertainty and the bias that one expert may bring into the decision problem.

\subsection{Probabilistic multi-criteria acceptability analysis (ProMAA)}

Probabilistic Multi-criteria Acceptability Analysis (ProMAA) is an MCDA method that can use distributions, rather than point values, for both weights and alternative utility scoring of criteria (Yatsalo, 2011; Linkov and Moberg, 2011; and see DECERNS-SDSS technical manual), allowing the user to account for both scoring and weighting uncertainties. The ProMAA algorithm utilizes the probability distributions of alternative scores and of weight coefficients for assessing rank acceptability indices based on pair-wise comparison of alternatives (Linkov and Moberg, 2011; Yatsalo et al., 2007; Yatsalo, 2011; and see DECERNS-SDSS technical manual). Thus, the overall utility of metric alternative $a_{i}, U\left(a_{i}\right)$, is:

$U\left(a_{i}\right)=p\left(w_{1}\right) w_{1} U_{1}\left(a_{i}\right)+\cdots+p\left(w_{j}\right) w_{j} U_{j}\left(a_{i}\right)$,

where $p\left(w_{j}\right)$ is the probability to observe the weight $w_{j}$ expressing stakeholders preference for criterion $j$ of any order in the value tree. The normalization condition for the weights still holds; however, unlike MAUT, ProMAA uses distributions instead of point values for the weights. In this case, the weights were determined by the authors and to each weight was assigned a standard deviation of 0.05 . The normalization condition is expressed analytically as:

$\sum_{j=1}^{m} p\left(w_{j}\right) w_{j}=1, \quad w_{j}>0, \quad 0 \leq p\left(w_{j}\right) \leq 1$,

The ProMAA algorithm can also utilize probability distributions of criteria utilities and weight coefficients for assessing probabilities of "likely rank events" (where events are associated with metrics in our decision problem) based on pairwise comparison of alternatives in an integrated scale. In this case realizations of ProMAA are based on numerical approximation of functions of random variables and numerical assessment of integrals (Yatsalo, 2011). "Rank acceptability indices" are the output of ProMAA. Rank acceptability indices are probabilities that describe the variety of different preferences resulting in a certain rank for an alternative (Lahdelma et al., 2004), and can be expressed as $P_{i_{k}}$ :

$P_{i_{k}}=P\left(S_{i_{k}}\right)$,

where $S_{i_{k}}$ is the event characterized by the metric alternative $a_{i}$ with rank $k$ and $i, k=1 \ldots n$ (i.e., $k-1$ alternatives are better than $a_{i}$ in terms of a given criteria for a subset of a space of elementary events). Thus, ranking or screening metrics $\left\{a_{i}, i=1, \ldots, n\right\}$ within ProMAA is based on the analysis of the matrix $\left\{P_{i k}\right\}, i, k=1, \ldots, n$. Rankings are based on the weighted overall score of $a_{i}$ against the criteria set $C$.

For the aggregation of the indicated probabilities, a weighted sum is typically used:

$P_{i}=\sum_{k=1}^{n} w_{k}^{a c} P_{i_{k}}$,

where $w_{k}{ }^{a c}$ are weights of relative importance of ranks (Lahdelma et al., 1998).

Thus, ranking or screening alternatives $\left\{a_{i}, i=1, \ldots, n\right\}$ within ProMAA is based on the analysis of the matrix $\left\{P_{i k}\right\}, i, k=1, \ldots, n$, and/or on the "holistic acceptability indices" $P_{i}, i=1, \ldots, n$, from which the average rank of alternatives $\bar{k}$ can be assessed.

Similar to the more commonly used probabilistic outranking method, and stochastic multi-objective acceptability analysis (SMAA), ProMAA accounts for uncertainty ranges in both criteria and weight values in its calculation of rank acceptability indices (Lahdelma et al., 2004). However, while software implementations of SMAA are based on Monte Carlo simulations (Tervonen and Figueira, 2008), ProMAA implementation is based on numerical approximation of random variables (Linkov and Moberg, 2011; Yatsalo et al., 2007; Yatsalo, 2011; and see DECERNS-SDSS technical manual). In this paper, we apply ProMAA to assess the importance of uncertainty in stakeholder preferences in determining alternatives ranking. In this case the alternatives are ecosystem restoration metrics.

Synthetically generated values can be assigned as standard probability distributions to criteria and preferences; thus, Monte 
Carlo simulations sample these distributions. In the majority of cases stakeholder preferences are elicited from workshops or using other methodologies (for example "serious games" (Nesloa and Cooke, 2011)) and their value and distribution can vary considerably. Criteria distributions are inferred from data or from stakeholder judgment. Thus, both preferences and criteria utilities are strongly case-specific and there is no standardized methodology to gauge and assign their distributions. For further technical details of ProMAA we direct readers to Yatsalo (2011) and to Linkov and Moberg (2011).

\section{Results and discussion}

The main objective of the paper was to provide methodological framework for a quantitative, structured, scalable, and transparent selection of metric alternatives. Metric selection is an extremely important aspect of environmental management; however it is often prone to high subjectivity that strongly affects both the selection and the evaluation of restoration projects. In this paper, we aimed to illustrate the use of a quantitative, structured and transparent metrics selection methodology, MCDA, to rank potential ecosystem restoration metrics. The results of this case study are discussed below.

The initial analysis, the Pareto-based domination analysis, eliminated nearly half of the potential metrics based solely on their partial utility with respect to each criterion. Specifically, this resulted in the identification and elimination of 18 dominated metrics, narrowing the metric pool from the initial comprehensive set of 43 aquatic ecosystem restoration metrics shown in Table 1 to the 25 non-dominated metrics shown in Fig. 2 . This greatly simplifies the decision and provides a clear and logical justification for removing dominated metrics independently of stakeholder preferences as they are sub-optimal under any set of weights.

The results of the MAUT and ProMAA models, that is, the average utility score for each of the metric alternatives, are shown in Fig. 3 . The average utility score is represented in the same range
$[0,1]$ for both methods. This type of visualization allows analysts to easily compare the utility of each metric as calculated by MAUT and ProMAA. For MAUT, the utility is calculated using Eq. (2), and for ProMAA using Equation 4. As many of the utility scores are similar to each other, this ranking is not intended to explicitly determine which metrics to use but it is an excellent guide for decision makers and clearly indicates that some metrics are more suitable than others (e.g. the metric local species richness is clearly more useful than geographic range of songbird). ProMAA enhances the ecological metrics according to the stakeholders' preference for ecological criteria, but overall the differences between the results of MAUT and ProMAA in terms of utilities of each of the metrics (Eqs. (2) and (4), respectively) are negligible. Despite that the average utility is higher for ProMAA, the rank of the metrics as a function of the utility score for ProMAA and MAUT is very similar.

The comparison of utilities from MAUT and ProMAA shows that the sensitivity of the selected metric set to the stakeholders' preferences is low. This may be related to the small uncertainty given to the weights for each criterion, or to the existence of an already well-defined set of metrics that were selected by a variety of experts in different fields. Certainly large variations in stakeholder preferences that are much bigger than the uncertainty assigned to the weights in this case study (Section 2.4) would cause bigger variation in the utility of each metrics. Thus, such variations in weights need to be considered in real practice. However, such large variability of weights is observed when different groups of stakeholders are considered for the same problem, or the same group of stakeholders is observed in time. Here, we consider uncertainty that is "small" and related to the assessment of stakeholder preferences. The application of global sensitivity and uncertainty analysis (Saltelli et al., 2008) in utility-based MCDA methods for evaluating the effect of large uncertainties is an ongoing effort and not the purpose of this paper.

Once the metrics ranking is formulated (Fig. 3) the decision about how many metrics to use should be a function of the available

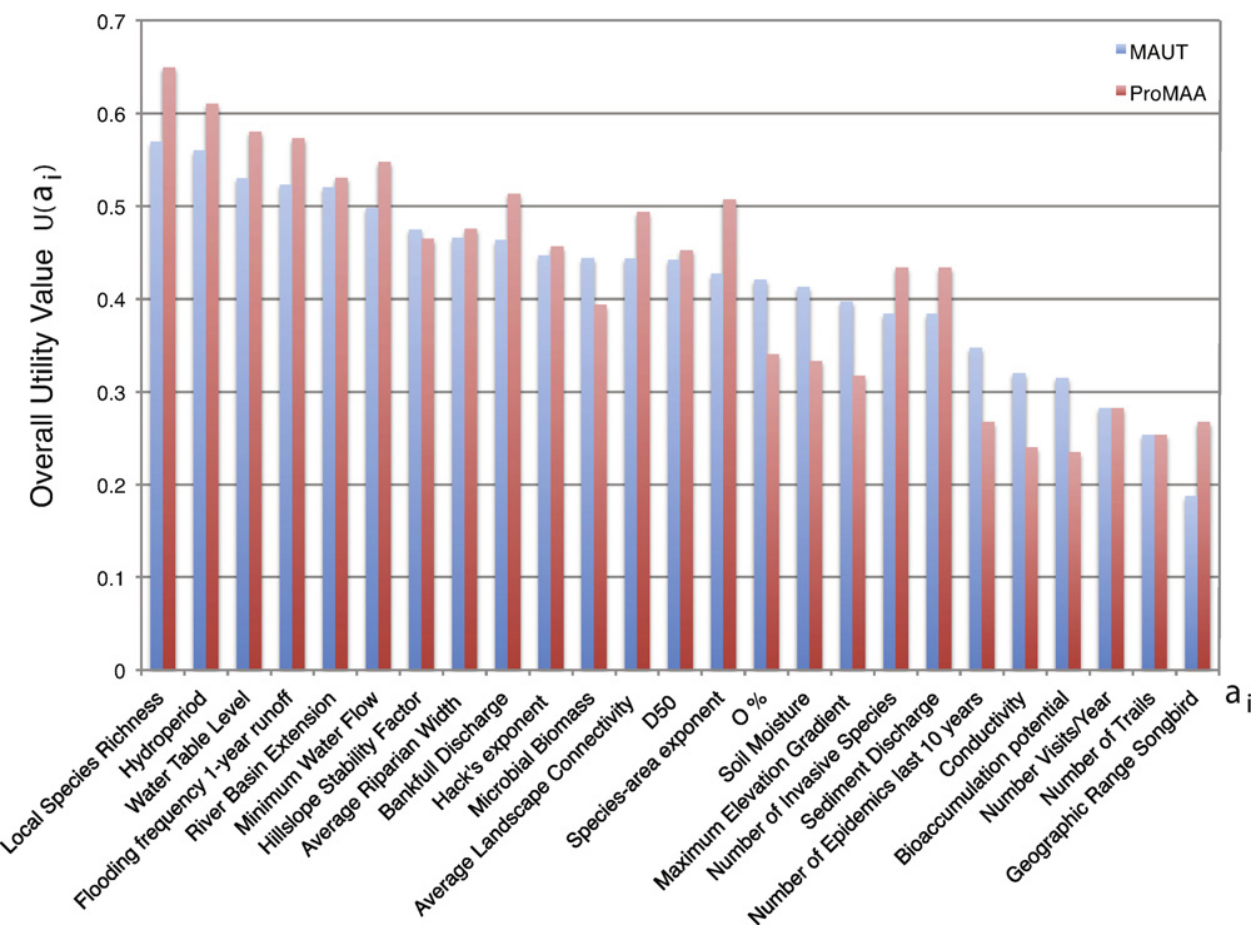

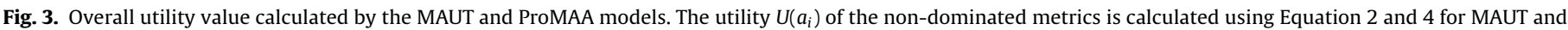

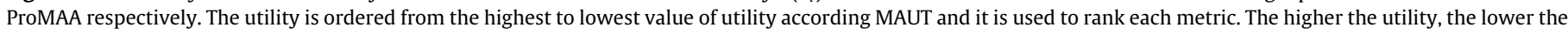
rank in a range $[1,25]$, where 25 is the number of non-dominated metrics. 


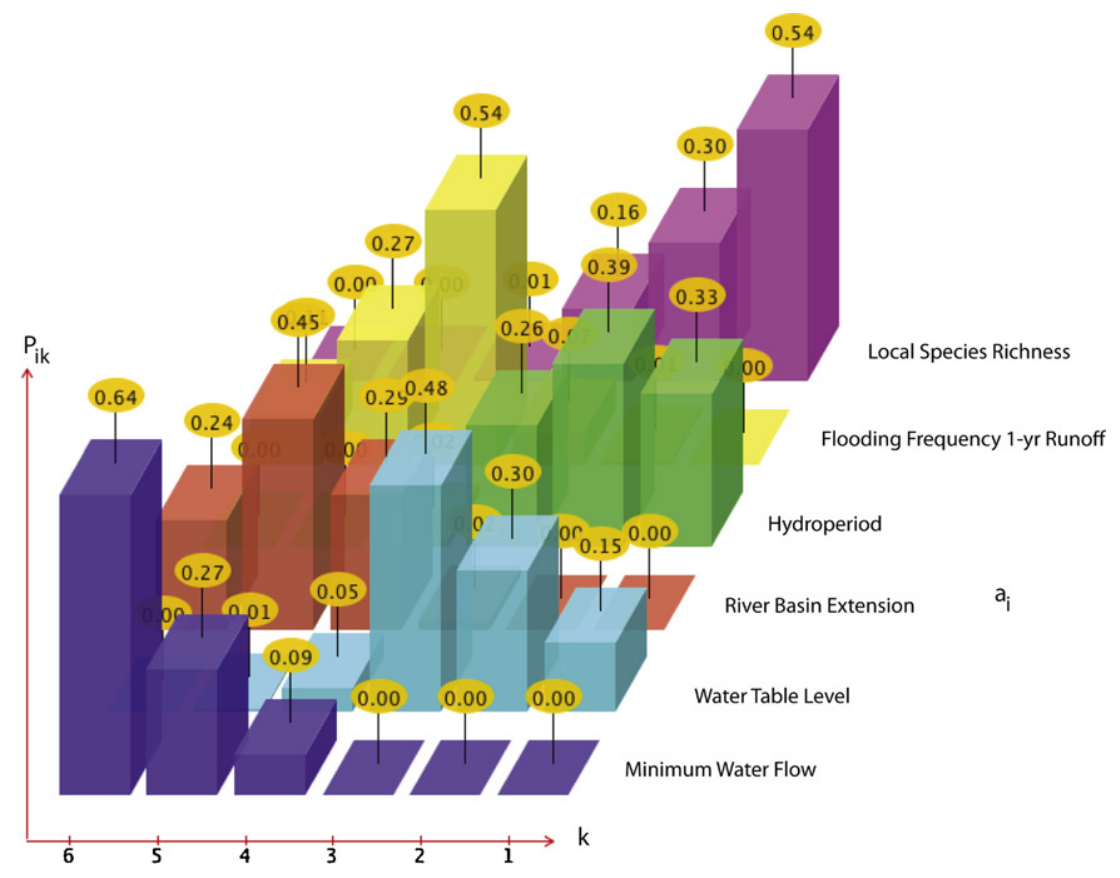

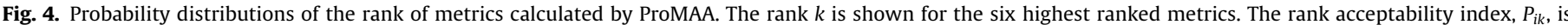

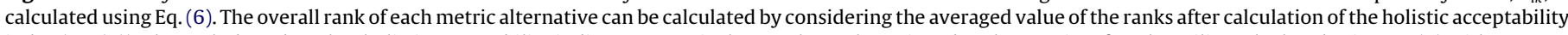

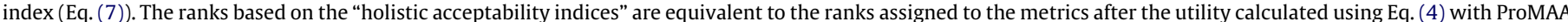

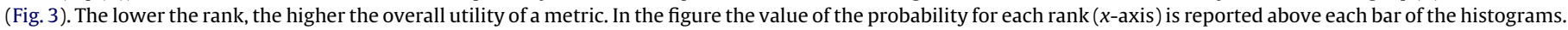

resources for monitoring those metrics. In this case study we do not consider this aspect that is highly specific to each restoration.

The predicted ranks of ProMAA considering the uncertainty in stakeholder preferences and in the utility of each metric for each criterion are represented by the probability distributions in Fig. 4. Metrics are characterized by a probability distribution of their rank (Eq. (6)) that is the result of the combined uncertainty of stakeholders' preferences (for MAUT the preferences are constant values, for ProMAA preferences are a distribution that accounts for uncertainty) and of utility values of metrics for each criterion. These ranks are also called "rank acceptability indices". The ranking order of metrics is established considering the average value of the distribution of each rank (Eq. (7)). In Fig. 4 we show an example of probability distributions of ranks for the six most valuable metrics. This is useful in showing the reliability of rankings in the face of uncertain inputs and how uncertainty affects metric ranking. The rank of metrics from ProMAA determined after calculating metrics' utility (Eq. (4)) or determined directly after calculating metrics' rank (Eq. (6)) is equivalent. This suggests that ProMAA can be used in both modes (probabilistic utility and outranking modes) without compromising the metric selection process. However, we believe that the utility is more useful information than the rank for a comparative analysis of metrics' utility. The difference in utility among sets of metrics or between two metrics can be interpreted as the value of information (Keeney and Raiffa, 1976) of a metric set or of a metric in the metric decision process. The value of information is in this case defined as the increase in the overall utility of a metric set arising from the predicted additional information of a metric prior to the metric selection.

\section{Conclusions and perspectives}

Selecting an appropriate and informative metrics set to monitor and evaluate ecosystem restoration projects is critical for informing management decisions of ecosystems, furthering the science, and updating restoration practices. With myriad metric choices and limited resources for monitoring, selecting the best metric set is often a difficult task (Noss, 1999; Dale and Beyeler, 2001; Niemeijer and de Groot, 2008). Current metrics selection methods, such as those based on best professional judgment or historical precedence are often inadequate for decision-making involving complex systems with multiple alternatives and evaluation criteria. MCDA, on the other hand, provides decision makers with a tool to clearly and transparently evaluate metric alternatives over a number of criteria while incorporating stakeholder values and expert opinions.

Moreover, MCDA limits the subjectivity in metric selection by incorporating stakeholder preferences into structured and quantitative models. By simultaneously considering the social, economic, and environmental components, the selected metrics aim to support more sustainable restorations.

In this study, we applied the MCDA methods, MAUT and ProMAA, to demonstrate how MCDA can be used to aid in metrics selection for aquatic restoration projects. We formulated a set of potential metrics for the hypothetical Black River restoration project, developed a taxonomy of weighted project objectives, screened the initial metrics set to remove dominated metrics, and finally applied MAUT and ProMAA to develop a list of metrics ranked according to their importance as a function of a set of stakeholder preferences and utility functions of each metric with respect to each criterion and sub-criterion. Utility-based methods are better suited to this type of analysis than value-based methods because they translate the value of metrics into utility to stakeholders. Moreover, ProMAA can incorporate uncertainty in stakeholder preferences that can be useful when a real elicitation of preferences is lacking or in cases where stakeholder preferences are highly uncertain. However, in our hypothetical case study, MAUT and ProMAA did not show significant differences in the predicted utility and ranking of the selected metrics.

Compared to the common metrics selection methods presented in the introduction (best professional judgment, historical precedence, conceptual modeling, screening using established criteria sets, and Analytic Hierarchy Process (Saathy, 1980)) MCDA is more 
comprehensive and inclusive, incorporating expert opinion on a variety of subjects and stakeholder preferences from several fields. This method allows planners to simplify complex situations with varied and often conflicting options, objectives, and opinions. New and changing information can also easily be integrated and evaluated. Interested parties can review components of the model including weights and alternative scores, and decision makers can clearly justify management choices according to model results. The MCDA method for metrics selection thus enables restoration project managers to make systematic, and transparent decisions. The quantitative results allow decision makers to clearly and easily compare each alternative and select the optimal metric set.

MCDA can be extremely beneficial, but it is also characterized by some limitations. Because it is so comprehensive and it includes input from a variety of stakeholders, it can be time consuming and more expensive than other, simpler metrics selection methods. Though, technically the project team alone could specify the criteria and weights, one of the cornerstones of MCDA methodology is involving stakeholders in the decision process. This means basing criteria and weighting partially on preferences elicited from stakeholders. It also takes a significant amount of work and expert judgment to assign value scores to each alternative for every criterion. Small increases in the amount of evaluation criteria and alternative choices translate to much larger increases in required input information. The number of evaluation criteria and metric alternatives is limited because each alternative must be evaluated with respect to each criterion. For example, in this case study 25 metrics were evaluated with respect to 7 criteria and 6 sub-criteria. This required 325 expert judgments of the value of each alternative with respect to each criterion as well as another 325 estimates of the certainty of those values.

Usually involving complex projects with serious stakeholder concerns, a successful MCDA evaluation often depends on stakeholder involvement, and is therefore limited by their willingness to participate (Linkov and Moberg, 2011). Also, the methodology is designed to narrow down chosen metric alternatives and does not include guidance for choosing the original larger metric set. Another method must be used to generate the metric alternatives that will be included in the MCDA analysis; perhaps one or a combination of the previously mentioned methods, such as historical precedence or best professional judgment, can be used to assemble the original metric set.

An MCDA technique should be used when many diverse stakeholders are interested in the project, and the situation is complex and/or high-profile with several objectives and alternatives under consideration. It is also useful with projects involving adaptive management as the situation can easily be updated and reevaluated, for example by new ecosystem restoration design, considering the monitored metrics. Restoration managers may find it useful to use screening before or after MCDA techniques to generate an initial list of metrics. We believe that overall this study provides a rigorous methodological and computational advancement to the current practice of metrics a utility-based selection for restoration design and monitoring, and in general for environmental management.

\section{Acknowledgements}

The authors acknowledge the support of the Environmental Benefit Analysis Program of the U.S. Army Corps of Engineers (http://cw-environment.usace.army.mil/eba/). Dr. B. Yatsalo is acknowledged for making a demonstration version of DECERNSSDSS available. D. Dokukin, and J.M. Keisler are kindly acknowledged for their support with DECERNS-SDSS and for the basis of the theoretical framework respectively. The Editor, Dr. F. Muller and two anonymous reviewers are gratefully acknowledged for their constructive comments. M.C. acknowledges the funding of project "Decision and Risk Analysis Applications Environmental Assessment and Supply Chain Risks" for his research at the Risk and Decision Science Team, Engineering Research and Development Center, U.S. Army Corps of Engineers, in Concord, MA, USA. C. Lu was BSc and MSc student at Massachusetts Institute of Technology, and research intern at the Risk and Decision Science Group when this research was performed. C. Lu is currently at AMEC Environment \& Infrastructure, Oakland, CA. Permission was granted by the U.S. Army Corps of Engineers - Chief of Engineers to publish this material. The views and opinions expressed in this paper are those of the individual authors and not those of the U.S. Army, or other sponsoring organizations.

\section{Appendix A. Supplementary data}

Supplementary data associated with this article can be found, in the online version, at http://dx.doi.org/10.1016/j.ecolind. 2012.10.005

\section{References}

Allen, E., Covington, W.W., Falk, D.A., 1997. Developing the conceptual basis for restoration ecology. Restor. Ecol. 5 (4), 275-276.

Belton, V., Stewart, T., 2002a. Multiple Criteria Decision Analysis: An Integrated Approach. Kluwer Academic Publishers, Dordrecht.

Belton, V., Stewart, T., 2002b. Multiple Criteria Decision Analysis: An Integrated Approach. Kluwer Academic Publishers, Boston.

Bettencourt, L.M.A., Kaur, J., 2011. Evolution and structure of sustainability science. PNAS, http://dx.doi.org/10.1073/pnas.1102712108.

Brans, J.P., Vincke, P., 1985. A preference ranking organisation method: the PROMETHEE method for MCDM. Manag. Sci. 31 (6), 647-656.

Braziunas, D., 2012. Decision-theoretic elicitation of generalized additive utilities, PhD thesis, University of Toronto, http://www.cs.toronto.edu/ darius/ papers/Darius_Braziunas_PhDThesis.pdf

Clark, W.C., 2007. Sustainability science: a room of its own. PNAS 104(6), 1737-1738, http://dx.doi.org/10.1073/pnas.0611291104.

Convertino, M., Baker, K., Lu, C., Vogel, J., McKay, K., Linkov, I., 2012. Metric Selection for Ecosystem Restoration, ERDC Technical Note, Environmental Benefits Analysis Program, US Army Corps of Engineering, forthcoming (http://cw-environment.usace.army.mil/eba/index.cfm).

Dale, V.H., Beyeler, S.C., 2001. Challenges in the development and use of ecological indicators. Ecol. Ind. 1, 3-10.

Diakoulaki, D., Karangelis, F., 2007. Multi-Criteria Decision Analysis and Cost-Benefit Analysis of alternative scenarios for the power generation sector in Greece. Renew. Sustain. Energy Rev. 11/4, 716-727.

Drechsler, M., Karin, F., Ilkka, H., O'Hara, R.B., Wissel, C., 2003. Ranking metapopulation extinction risk: from patterns in data to conservation management decisions. Ecol. Appl. 13, 990-998, http://dx.doi.org/10.1890/1051-0761(2003)13.

Ehrenfeld, J.G., 2000. Defining the limits of restoration: the need for realistic goals. Restor. Ecol. 8 (1), 2-9.

Emmerich, M., Deutz, A., 2006. Multicriteria Optimization and Decision Making, Principles, Algorithms and Case Studies, Leiden Institute of Advances Computer Studies, http://citeseerx.ist.psu.edu/viewdoc/summary?doi=10.1.1.162.694

Faber-Langendoen, D., Rocchio, J., Schafale, M., Nordman, C., Pyne, M., Teague, J., Foti, T., Comer, P., 2006. Ecological Integrity Assessment and Performance Measures for Wetland Mitigation. Final Report to US Environmental Protection Agency Office of Wetlands, Oceans and Watersheds, NatureServe, Arlington, VA.

Figueira, J., Greco, S., Ehrgott, M. (Eds.), 2005. Multiple Criteria Decision Analysis: State of the Art Surveys. Springer Science+Business Media, Boston, USA.

Gass, S.I., 2005. Model world: the great debate-MAUT versus AHP. Interfaces 35 (4), 308-312.

Georgopoulou, E., Lalas, D., Papagiannakis, L., 1997. A multicriteria decision aid approach for energy planning problems: the case of renewable energy option. Eur. J. Operat. Res. 103, 483-500.

Grootjans, A.P., Geelen, H.W.T., Jansen, A.J.M., Lammerts, E.J., 2002. Restoration of coastal dune slacks in the Netherlands. Hydrobiologia 478, 181-203.

Holmes, N., 1991. Post-project appraisal of conservation enhancements of flood defence works. R\&D Report 285/1/A, National Rivers Authority, Reading UK.

Huang, I.B., Keisler, J., Linkov, I., 2011. Multi-criteria decision analysis in environmental sciences: ten years of applications and trends. Sci. Total Environ. 409 (19), 3578-3594, http://dx.doi.org/10.1016/j.scitotenv.2011.06.022.

Kaminaris, S., Tsoutsos, T., Agoris, D., Machias, A., 2006. Assessing renewables-toelectricity systems: fuzzy expert system model. Energy Policy No 34, 1357-1366.

Keeney, R.L., 1977. The art of assessing multiattribute utility functions. Organ. Behav. Hum. Perform. 19 (August (2)), 267-310.

Keeney, R.L., Gregory, R.S., 2005. Selecting attributes to measure the achievement of objectives. Operat. Res. 53 (1), 1-11.

Keeney, R.L., Raiffa, H., 1976. Decision with Multiple Objectives: Preferences and Value Tradeoffs. John Wiley \& Sons, New York. 
Kondolf, G.M., 1995. Five elements for effective evaluation of stream restoration Restor. Ecol. 3 (2), 133-136.

Lahdelma, R., Hokkanen, J., Salminen, P., 1998. SMAA-stochastic multi-objective acceptability analysis. Eur. J. Operat. Res. 106, 137-143.

Lahdelma, R., Makkonen, S., Salminen, P., 2004. Treating dependent uncertainties in multi-criteria decision problems. In: Rao, M.R., Puri, M.C. (Eds.), Operational Research and Its Applications: Recent Trends, Vol. II New Delhi. pp. 427-434.

Linkov, I., Moberg, E., 2011. Multi-Criteria Decision Analysis: Environmental Applications and Case Studies. CRC Press.

Loken, E., 2007. Use of multicriteria decision analysis methods for energy planning problems. Renew. Sustain. Energy Rev. 11, 1584-1595.

Martine, M., Cockfield, G., 2008. Managing trade-offs in landscape restoration and revegetation projects. Ecol. Appl. 18, 2041-2049, http://dx.doi.org/10.1890/ 07-1328.1.

McKay S.K., Linkov I., Fischenich J.C., Miller S.J., Valverde L.J. Jr., 2011. Ecosystem Restoration Objectives and Metrics, USACE ERDC Technical Note.

Mexas, M.P., Goncalves Quelhas, O.L., Gomes Coasta, L., 2012. Prioritization of enterprise resource planning systems criteria: Focusing on construction industry. Int. J. Product. Econ., http://dx.doi.org/10.1016/j.ijpe.2012.05.025.

National Academy of Sciences. 2012. Ecosystem Services: Charting a Path to Sustainability, Interdisciplinary Research Team Summaries, National Academy of Sciences Press, http://download.nap.edu/cart/download.cgi? \&record_id $=13331$ \&free $=1$

Nesloa, R.E.J., Cooke, R.M., 2011. Modeling and validating stakeholder preferences with probabilistic inversion. Appl. Stoch. Model. Bus. Ind., http://dx.doi.org/10.1002/asmb.888

Niemeijer, D., de Groot, R.S., 2008. A conceptual framework for selecting environmental indicator sets. Ecol. Indicat. 8, 14-25.

Nienhuis, P.H., Bakker, J.E., Grootjans, A.P., Gulati, R.D., De Jonge, V.N., 2002. The state of the art of aquatic semi-aquatic ecological restoration projects in the Netherlands. Hydrobiologia 478, 219-233.

Noss, R.F., 1999. Assessing and monitoring forest biodiversity: a suggested framework and indicators. Forest Ecol. Manage. 115, 135-146.

Palmer, M.A., Reidy Liermann, C.A., Nilsson, C., Florke, M., Alcamo, J., Lake, P.S., Bond, N., 2008. Climate change and the World's River Basins: anticipating management options. Front. Ecol. Environ. 6, 81-89.

Pauly, D., Christensen, V., Guenette, S., Pitcher, T.J., Sumaila, U.R., Walters, C.J., Watson, R., Zeller, D., 2002. Towards sustainability in world fisheries. Nature 418, 689-695.

Phillis, Y.A., Andriantiatsaholiniana, L.A., 2001. Sustainability: an ill-defined concept and its assessment using fuzzy logic. Ecol. Econ. 29, 235-252.

Pohekar, S.D., Ramachandran, M., 2004. Application of multi-criteria decision making to sustainable energy planning-a review. Renew. Sustain. Energy Rev. 8 (4), 365-381.
Reichert, P., Borsuk, M., Hostmann, M., Schweizer, S., Spörri, C., Tockner, K., Truffer, B., 2007. Concepts of decision support for river rehabilitation. Environ. Model Software 22, 188-201.

Rohde, S., Kienast, F., Bürgi, M., 2004. Assessing the restoration success of river widenings: a landscape approach. Environ. Manage. 34, 574-589.

Saathy, T.L., 1980. The Analytic Hierarchy Process: Planning, Priority Setting, Resource Allocation. McGraw-Hill, New York.

Saltelli, A., Ratto, M., Andres, T., Campolongo, F., Cariboni, J., Gatelli, D., 2008. Global Sensitivity Analysis: The Primer. John Wiley \& Sons Ltd.

Seager, T.P., Satterstrom, F.K., Linkov, I., Tuler, S.P., Kay, R., 2007. Typological review of environmental performance metrics (with illustrative examples for oil spill response). Integr. Environ. Assess. Manag. 3 (3), 310-321.

Settin, T., Botter, G., Rodriguez-Iturbe, I., Rinaldo, A., 2007. Numerical studies on soil moisture distributions in heterogeneous catchments. Water Resour. Res. 43, W05425.

Sigrid, S., 2004. Valuation for sustainable development - the role of multicriteria evaluation. Vierteljahreshefte zur Wirtschaftsforschung (Quart. J. Econ. Res.) 73 (1), 1-10.

Tervonen, T., Figueira, J.R., 2008. A survey on stochastic multicriteria acceptability analysis methods. J. Multi-Criteria Decision Anal. 15 (1-2), 1-14.

Thayer G.W., Merkey D.H., McTigue T.A., Burrows F.M., Salz R.J., Gayaldo P.F. 2005. Science based restoration monitoring of coastal habitats. Decision Analysis Series, No. 23 Vol. 2. NOAA.

Thom, R.M., Wellman, K.F., 1996. Planning aquatic ecosystem restoration monitoring programs. Pacific Northwest National Laboratory, Richland, Washington; fina report prepared for US Army Corps of Engineers, Institute for Water Resources, Alexandria, VA, IWR Report 96-R-23.

Tsoutsos, T., Tsouchlaraki, A., Tsiropoulos, M., Serpetsidakis, M., 2009. Visual impact evaluation of a wind park in a Greek island. Appl. Energy 86 (5), 1587-1600.

U.S. Army Corps of Engineers (USACE). 1999. Civil Works Ecosystem Restoration Policy. ER 1165-2-501.

von Winterfeldt, D., Edwards, W., 1986. Decision Analysis and Behavioral Research. Cambridge University Press, Cambridge.

Wood, M.D., Bostrom, A., Bridges, T., Linkov, I., 2012.Cognitive mapping tools: review and risk management needs. Risk Anal. 32 (8), 1333-1348.

World Economic Forum. 2011. Global Risks 2011 Sixth Edition: An initiative of the Risk Response Network, World Economic Forum Press, http://reports. weforum.org/global-risks-2011/

2011. DECERNS-SDSS: Decision Evaluation in Complex Risk Network Systems www.decerns.com

Yatsalo, B.I., Gregory, A., Kiker, A., Kim, J., Bridges, T.S., Seager, T.P., Gardner, K., Satterstrom, F.K., Linkov, I., 2007. Application of multicriteria decision analysis tools to two contaminated sediment case studies. Integr. Environ. Assess. Manag. 3 (2), 223-233. 